\title{
Ugly Truths: A Review of Jan Smitowicz, Orange Rain: A Revenge Novel
}

\author{
Nicole Barbaro $^{1} \cdot$ Todd K. Shackelford ${ }^{1}$
}

Published online: 19 April 2016

(C) Springer International Publishing 2016

He keeps wondering how the human psyche can take so much trauma, so much shit, and stay intact. Stay functional.

-Max, Orange Rain (2014; p. 192)

Abortion, addiction, procreation, rape, and suicide - these are topics most people are familiar with, either personally or by association. Although there is intense interest in these topics, they receive relatively little open discussion - in part, because each of these issues stirs deep moral philosophies and evokes controversial and divergent opinions. Controversial topics such as these are often absent from public discussion, or worse, discussion of these issues is censored or avoided.

Enter: Jan Smitowicz. He brilliantly accomplishes the daunting task of exploring each of these topics (and many more) in a single manuscript. Smitowicz utilizes a unique medium to broach such important personal and societal issues: a fiction novel. Orange Rain: A Revenge Novel follows Vietnam War veteran, Max Wright, on his revenge journey against Monsanto Corporation. The novel is set in the mid1980s USA, but the issues plaguing individuals and society then are still relevant in today's society. From one astonishing scene to the next, Smitowicz boldly transcends the line between honesty and absurdity, including shocking portrayals of amputee porn, rape (twice), and murder.

Despite the wild nature of Orange Rain, a single thread weaves through Max's revenge journey: the wondrous ability

Nicole Barbaro

nmbarbar@oakland.edu

1 Department of Psychology, Oakland University, 108 Pryale Hall, Rochester, MI 48309, USA of humans to suffer so deeply and tragically, yet continue onward. Smitowicz elegantly unveils the "grotesque horrorshow of modern life" in his writing. Although shocking at times, he offers unapologetic and profound insights regarding the ugly truths of how people deal with personal tragedy and suffering. Chapter 6 of Orange Rain provides a particularly deep and honest discussion between the story's characters about the lengths to which people sometimes go to numb their pain. Smitowicz brings clear and vivid awareness to the dark rabbit hole of drug abuse, depression, and suicide, even embarking on a "tangential indulgence" in Chapter 2 to highlight how serious and tragic suicide is.

Smitowicz's discussion of the inevitable suffering humans endure throughout life provides a platform to advocate antinatalism. The argument that being born is always a serious harm and, therefore, that producing children is morally indefensible (i.e., antinatalism) is hotly debated (see Benatar and Wasserman 2015). Smitowicz, unsurprisingly, does not shy away from this topic, but instead embraces it. Chapter 5 follows Max to San Antonio, Texas, where he meets a group of social activists. Smitowicz depicts a conversation between the characters in which the social activists explain to Max and his friends that procreation is a major obstacle to social revolution, and that all the men in the activist group have had vasectomies to prevent procreation - mirroring the real-life choices and philosophical positions of the author.

The vigor with which Smitowicz approaches these issues, if pursued by evolutionary psychological analysis, might improve our understanding of these phenomena. Depression and suicide are often portrayed as pathological. An evolutionary psychological perspective, however, might suggest otherwise. Evolutionary models of psychopathology (e.g., Del Giudice 2016) posit that pathology arises when evolved psychological mechanisms are not functioning as they were "designed" to function, or when evolved psychological mechanisms 
produce behavior not conducive to well-being in the modern environment (i.e., evolutionary mismatches).

Application of evolutionary models of psychopathology may yield insight into why depression and suicide occur. Several lines of reasoning have been advanced concerning the evolved function of depression (Andrews and Thomson 2009; Nesse 2000). More generally, it is posited that depression functions to reduce engagement and resource investment into unpropitious goals. The "analytical rumination hypothesis" specifically argues that depression is an evolved response facilitating complex problem-solving strategies (Andrews and Thomson 2009). Complex problems social in nature (e.g., cooperation, competition, mating) may be the evolutionaryrelevant trigger of depressive symptoms. Because depression increases the risk of suicide attempt, suicide, then, may reflect an inability to solve a particular social problem one is facing. Although suicide appears paradoxical in an evolutionary sense, suicide behavior may have produced benefits for kin in ancestral environments. For example, the "inclusive fitness model" of suicide suggests that individuals may benefit the replicative success of kin via self-sacrifice (e.g., Joiner et al. 2015; Syme et al. 2015).

In Chapter 7 of Orange Rain, Smitowicz delves into another important social issue: abortion. Abortion is one of the most morally contested topics in today's society, generating heated debate in public, private, and political spheres. In Orange Rain, Max's girlfriend, Mai Linh, becomes pregnant as the result of rape. Smitowicz takes a clear pro-choice stance in his story and highlights several important issues regarding abortion rights in the USA. He depicts the dismal state of women's access to abortion, illustrated by the difficulty Max has to simply acquire information about how to access an abortion provider. Smitowicz further illustrates the public judgment passed on women for seeking or having an abortion and honestly depicts the safety concerns that women (and providers) face when seeking abortion. The state of abortion rights in the USA is not improving and, arguably, is worsening. For example, in just the brief period between 2011 and 2013, more than 200 state laws have been passed that further restrict women's access to abortion - more laws than had been passed in the previous decade (see Pollitt 2014).

Moreover, evolutionary perspectives have revealed that induced abortion is not a modern phenomenon but, instead, that the killing of offspring (via abortion prior to birth or infanticide following birth) is rife in the historical record and comparative literature (see Hudson and den Boer 2004). Thus, abortion may reflect proper functioning of psychological mechanisms designed for infanticide that facilitate the survival of parents and other offspring-with the advent of modern technology affording women safe, medical abortions (legal abortion procedures are, in fact, medically safer than childbirth; see Pollitt 2014). Evolutionary psychological research could investigate whether the ecological conditions predictive of infanticide (e.g., scarce resources, nursing older offspring) also predict induced abortion (e.g., Hrdy 1979; Hudson and den Boer 2004).

In his debut novel, Smitowicz highlights important issues of human existence that are worthy of scientific analysis. Orange Rain is a shockingly good read: engaging, facedpaced, and ever-entertaining. But, Smitowicz takes fiction writing a step further. He elegantly interweaves several deeply unsettling topics of human existence using an accessible, fiction medium to tackle a breadth of social issues that are anything but fiction. Orange Rain is highly recommended for those seeking a cannot-put-down novel, and for those interested in the important topics permeating Max's revenge journey. Orange Rain is a fictional novel with an engagingly absurd story line, but the messages and views expressed by Smitowicz are profoundly, and honestly, real.

\section{References}

Andrews, P. W., \& Thomson, J. A., Jr. (2009). The bright side of being blue: depression as an adaptation for analyzing complex problems. Psychological Review, 116, 620-654.

Benatar, D., \& Wasserman, D. (2015). Debating procreation: is it wrong to reproduce? New York: Oxford University Press.

Del Giudice, M. (2016). The life history model of psychopathology explains the structure of psychiatric disorders and the emergence of the p factor: a simulation study. Clinical Psychological Science, 4, 299-311.

Hrdy, S. B. (1979). Infanticide among animals: a review, classification, and examination of the implications for the reproductive strategies of females. Ethology and Sociobiology, 1, 13-40.

Hudson, V. M., \& Den Boer, A. M. (2004). Bare branches: the security implications of Asia's surplus male population. Cambridge: MIT Press.

Joiner, T. E., Hom, M. A., Hagan, C. R., \& Silva, C. (2015). Suicide as a derangement of the self-sacrificial aspect of eusociality. Psychological Review, 123, 235-254.

Nesse, R. M. (2000). Is depression an adaptation? Archives of General Psychiatry, 57, 14-20.

Pollitt, K. (2014). Pro: reclaiming abortion rights. New York: Picador.

Smitowicz, J. (2014). Orange rain: a revenge novel. Los Angeles: Trebol Press.

Syme, K. L., Garfield, Z. H., \& Hagen, E. H. (2015). Testing the bargaining vs. inclusive fitness models of suicidal behavior against the ethnographic record. Evolution and Human Behavior. Manuscript in press. 